\title{
Macrodystrophia lipomatosa
}

\author{
Author: \\ Andrew J. van den Heever ${ }^{1}$ \\ Affiliation: \\ ${ }^{1}$ Tuft and Partners \\ Incorporated Radiologists, \\ Cape Town, South Africa \\ Correspondence to: \\ Andrew van den Heever \\ Email: \\ andrew.vdh@tuft.co.za \\ Postal address: \\ PO Box 461, Plumstead \\ 7801, South Africa \\ Dates: \\ Received: 09 June 2014 \\ Accepted: 10 Nov. 2014 \\ Published: 15 Dec. 2014 \\ How to cite this article: \\ Van den Heever, AJ. \\ Macrodystrophia lipomatosa. \\ S Afr J Rad. 2014;18(2); \\ Art. \#667, 4 pages. \\ http://dx.doi.org/10.4102/ \\ sajr.v18i2.667

\section{Copyright:} \\ C 2014. The Authors. \\ Licensee: AOSIS \\ OpenJournals. This \\ work is licensed under \\ the Creative Commons \\ Attribution License.
}

\section{Read online:}

Macrodystrophia lipomatosa (MDL) is a rare congenital, but non-hereditary, form of localised gigantism of the fingers or toes. The hallmark of the condition is hypertrophy of all mesenchymal elements in the involved region, with a predominance of fibro-adipose tissue. A clinically subtle case of MDL is presented.

\section{Introduction}

A clinically subtle case of macrodystrophia lipomatosa (MDL) of the left hand is presented, with emphasis on the characteristic magnetic resonance imaging (MRI) features of the condition that assisted in the radiological diagnosis.

\section{Case presentation}

A 16-year-old girl presented with a swollen, erythematous and warm left hand of long-standing duration (Figure 1). The initial clinical suspicion included cellulitis or a retained foreign body. There was no trophic skin change, and the neuromuscular examination of the limb was normal.

Following a plain radiograph of the left hand (Figure 2), an ultrasound scan was requested; a diagnosis of MDL was suggested, based on the findings of excessive fatty and vascular elements within a region of relative hypertrophy matching that of the median nerve sclerotome (Figure 3).

Magnetic resonance imaging (MRI) confirmed the diagnosis and excluded vascular or lymphatic malformation. The patient was scanned with both hands and wrists together (palms facing) to demonstrate the asymmetrical fatty and vascular hypertrophy (Figures 4-7.)

\section{Discussion}

MDL is a rare congenital, but non-hereditary, form of localised gigantism of the fingers or toes with progressive proliferation of all mesenchymal elements in the distribution of a sclerotome and a disproportionate increase in fibro-adipose tissue. ${ }^{1,2,3}$ It can involve both the upper extremities (usually in the distribution of the median nerve with the index and middle fingers most commonly involved) and the lower extremities (usually in the distribution of the medial plantar nerve). ${ }^{4}$ MDL is mostly unilateral, with lower limb involvement more common.

Accelerated soft-tissue and osseous growth in the involved region is self-limiting and usually terminates at puberty. ${ }^{5}$ MDL may be associated with syndactyly, polydactyly, brachydactyly or clinodactyly. ${ }^{4}$

The hallmark of MDL is hypertrophy of all mesenchymal elements in the involved region, with a predominance of fatty tissue. Fibro-adipose tissue is produced in association with localised hyperplastic vascular and lymphatic elements. ${ }^{6}$

The pathologic findings are infiltration and hypertrophy of adipose tissue in subcutaneous tissue, nerve sheaths and periosteum. ${ }^{5}$ Proposed aetiologies include disturbed foetal circulation, trophic influence of a tumified nerve, in utero disturbance of growth-limiting factor, or an error in segmentation. ${ }^{7}$

The differential diagnoses include neurofibromatosis type 1, vascular malformation, fibrolipomatous hamartoma of the median nerve, Klippel-Trenaunay-Weber syndrome and hemihypertrophy (Proteus and Beckwith-Wiedemann syndromes). ${ }^{8}$

Treatment goals are to (1) maintain nerve and joint function by minimising local tissue trauma; and (2) improve cosmesis. Surgical management includes inter alia debulking, epiphyseodesis and osteotomy. 


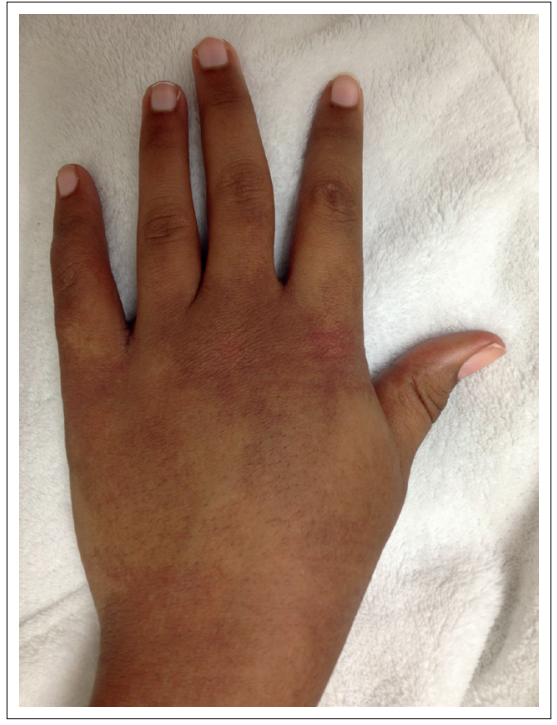

FIGURE 1: Photograph of the left hand. Subtle hypertrophy of the third digit.

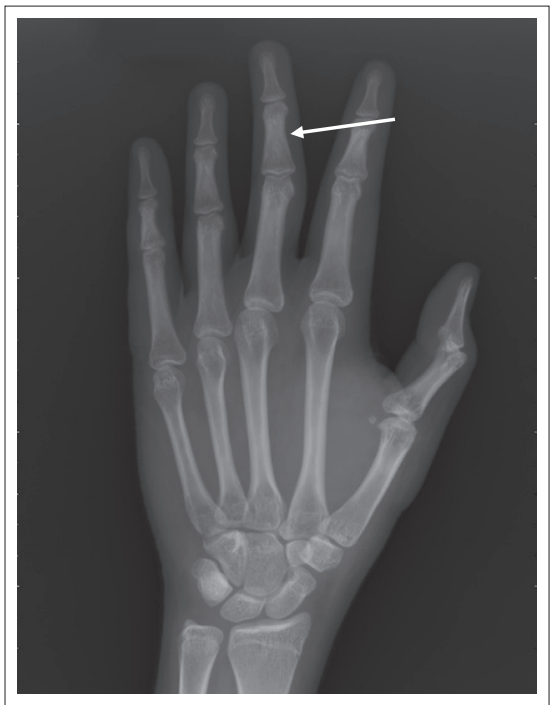

FIGURE 2: Plain radiograph of the left hand. Note hypertrophied soft tissues around the second and third digits and elongation of the third digit.
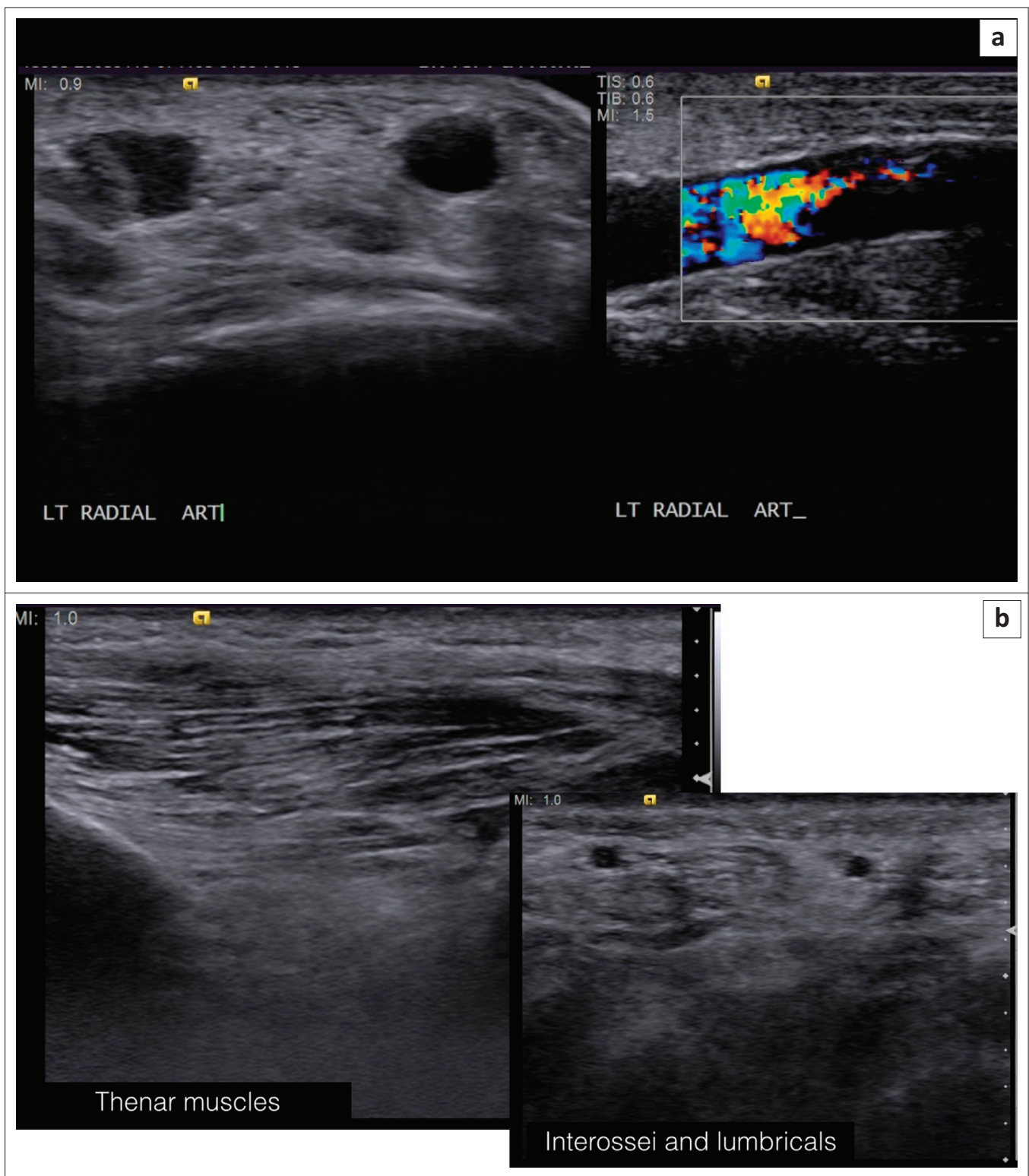

FIGURE 3: Ultrasound of the left hand shows (a) increased diameter of the radial artery, but no vascular malformation, and (b) linear increased reflectivity of the thenar, interossei and lumbrical muscles consistent with fatty infiltration. Note: this differs from denervation change where the muscle bulk is decreased. 
Plain radiographs usually demonstrate the osseous overgrowth in the involved digits. However, in cases such as the present, where the hypertrophy is not marked, it may be overlooked. This case also demonstrates how the fatty overgrowth typical in MDL may be confusing on ultrasound examination. The diffuse fatty hypertrophy in the subcutaneous tissues and within the intrinsic musculature all appears diffusely echogenic, which results in a loss of soft-tissue detail and a decrease in the extent of grey-scale difference (reflectivity) between soft-tissue structures.
The key to making the diagnosis on ultrasound is recognising the abnormal tissue echogenicity consistent with increased fat. MRI is the investigation of choice owing to its superior soft-tissue contrast and its ability to characterise soft tissue, particularly fat. The contrast between fat and muscle allows effective visualisation of fatty infiltration of muscle; this can be confirmed with fat suppression techniques. Increased vascularity is also clearly visualised as vascular flow-voids or by performing MR angiography.

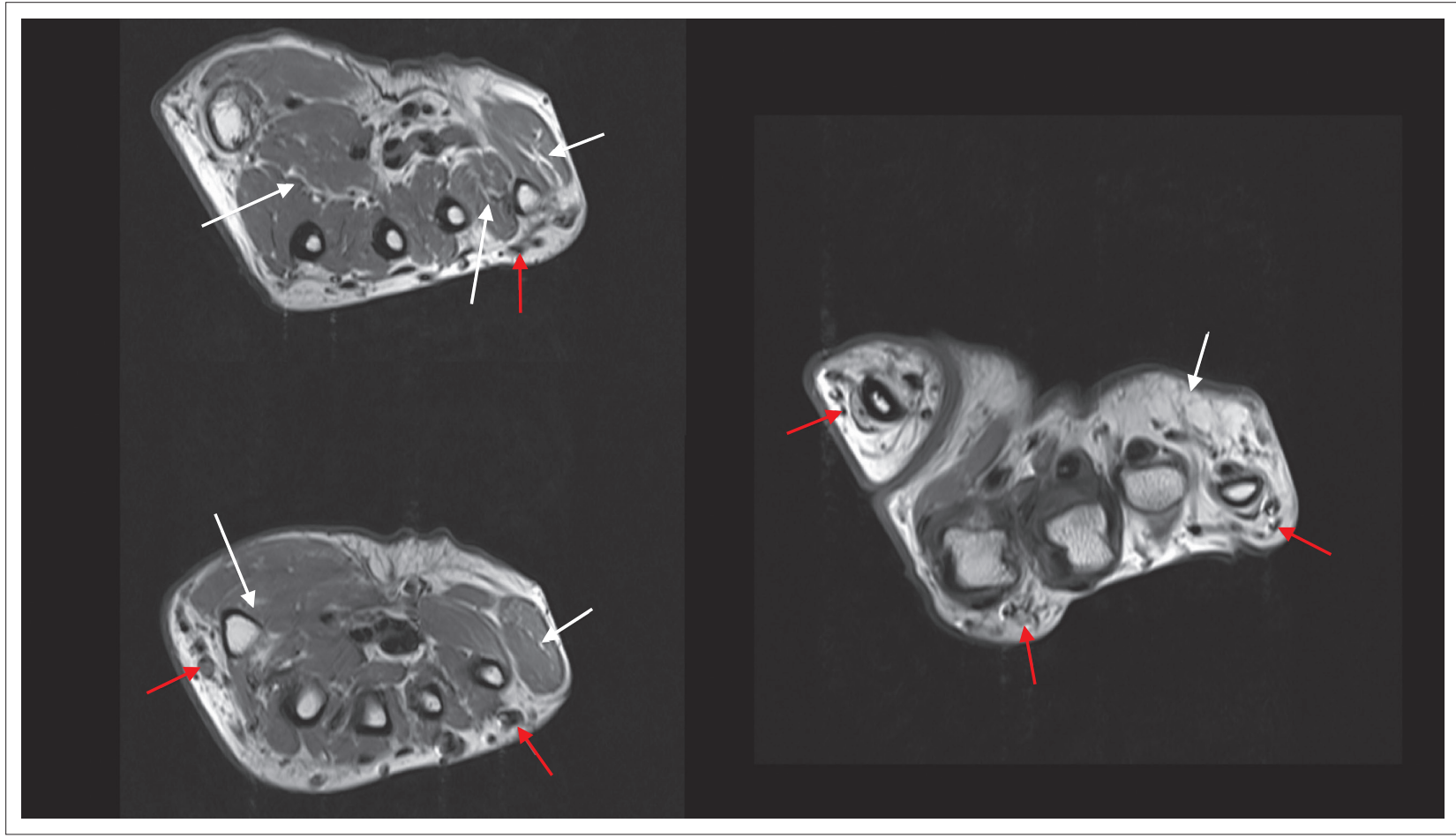

FIGURE 4: Axial T1-weighted fast spin echo (FSE) images demonstrate increased subcutaneous and intramuscular fat (white arrows) with numerous prominent vascular structures throughout the subcutaneous tissues (red arrows).
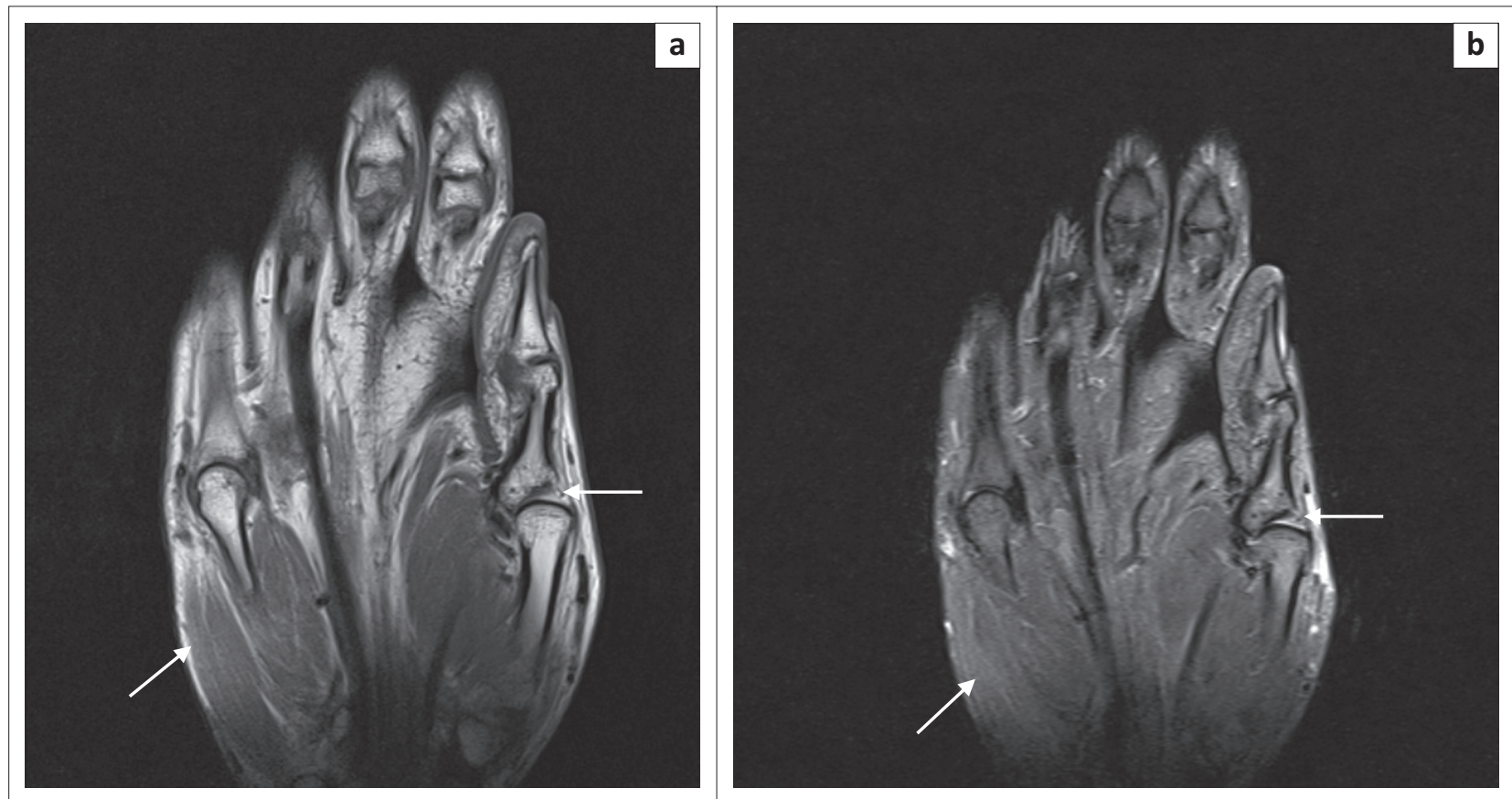

FIGURE 5: T1 FSE coronal image of the left hand (a) and PD fat-saturated coronal image (b) prominent subcutaneous and intramuscular fat (arrows). 

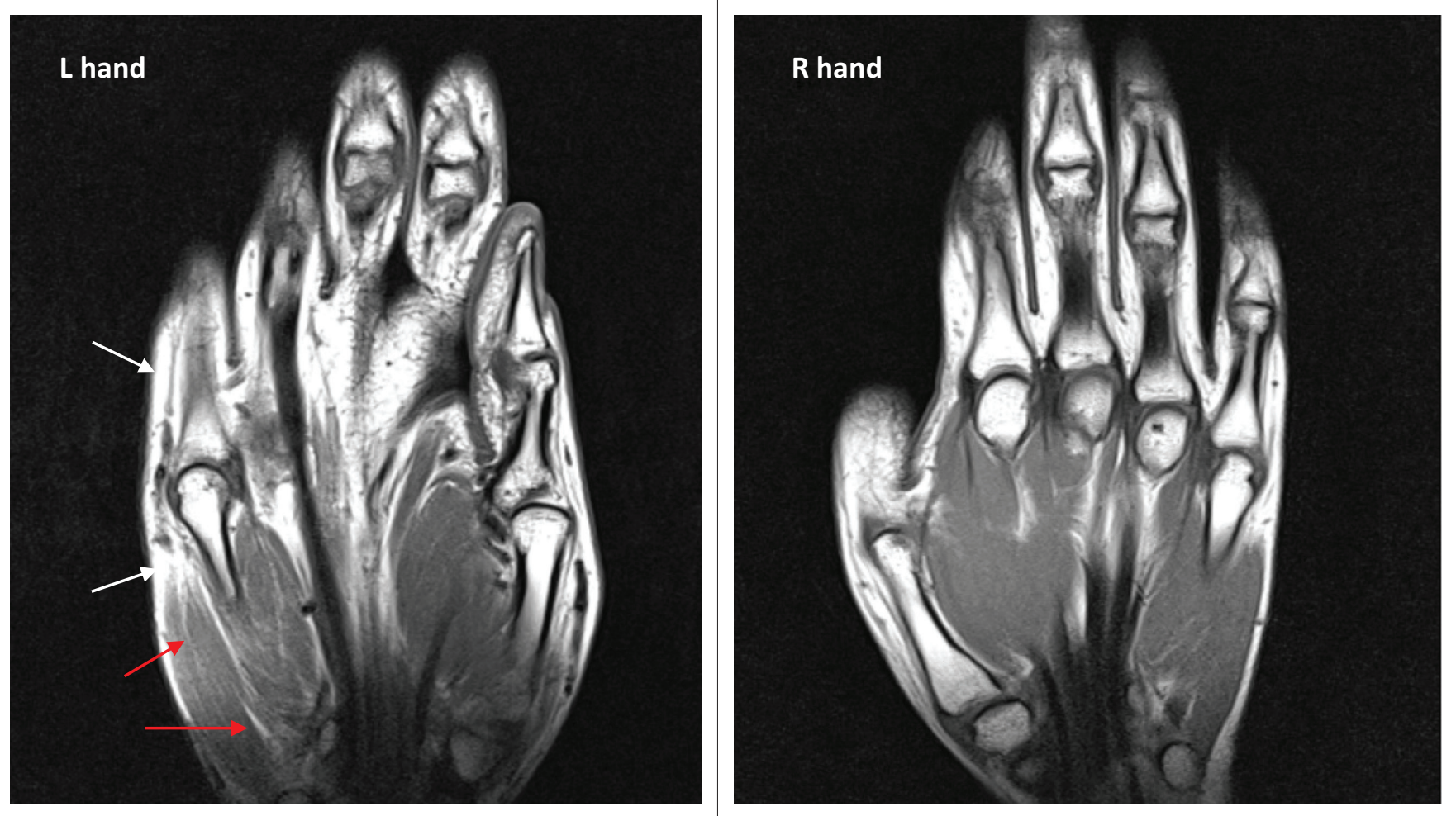

FIGURE 6: Comparative coronal T1 FSE images of the right and left hands (acquired in a single volume). The increased subcutaneous fat (white arrows) and intramuscular fat (red arrows) as well as the hemihypertrophy of all of the mesenchymal elements in the left hand are easily appreciated when compared with the unaffected right hand.

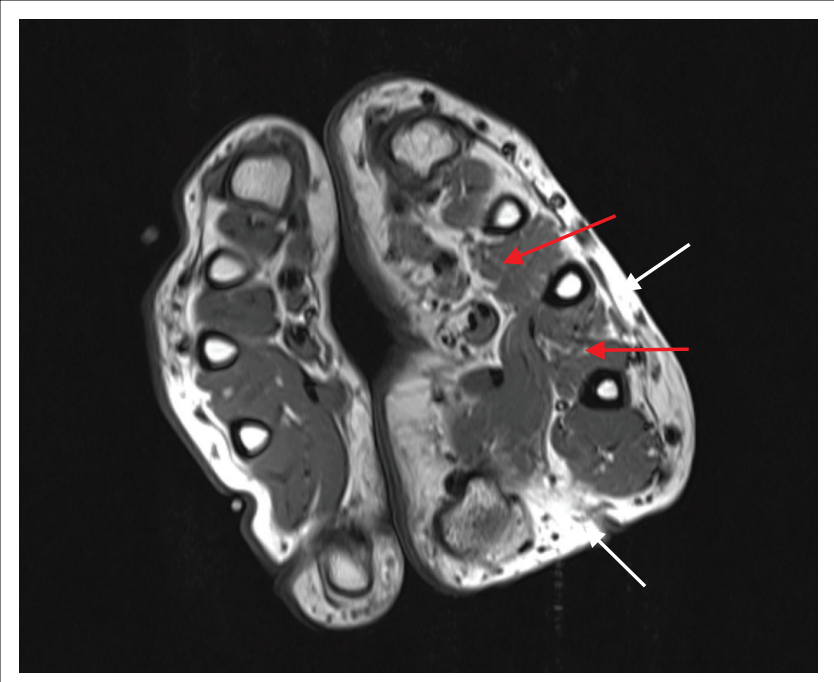

FIGURE 7: Comparative axial T1 FSE images of the right and left hands (acquired in a single volume). The increased subcutaneous fat (white arrows) and intramuscular fat (red arrows) as well as the hemihypertrophy of all of the mesenchymal elements in the left hand are easily appreciated when compared with the unaffected right hand.

\section{Conclusion}

MDL is a rare congenital form of localised gigantism. In cases such as the present, where the hypertrophy of involved tissues is not marked, the condition may be missed or incorrectly diagnosed. In such cases, MRI is the investigation of choice owing to its ability to differentiate and characterise soft-tissue structures. Ultrasound is useful in excluding conditions included in the clinical differential diagnosis, but may be misleading owing to the uniform echogenicity of structures infiltrated by fat.

\section{Acknowledgements Competing interests}

The author declares that they he has no financial or personal relationships that he might have inappropriately influenced him in writing this article.

\section{References}

1. Singla V, Virmani V, Tuli P, Singh P, Khandelwal N. Case Report: Macrodystrophia lipomatosa - Illustration of two cases. Indian J Radiol Imaging. 2008; 18(4): 298301. http://dx.doi.org/10.4103/0971-3026.43844

2. Suleman FE, Kisansa M. Imaging of a rare disorder: macrodystrophia lipomatosa. S Afr J Rad. 2010; 14(2): 39-42.

3. Aga P, Parashari UC, Parihar A, et al. Macrodystrophia lipomatosa - MR imaging of a rare congenital anomaly: review of 3 cases. S Afr J Rad. 2010; 14(4): 105-107.

4. Khan RA, Wahab S, Ahmad I, Chana RS. Macrodystrophia lipomatosa: four case reports. Ital J Pediatr. 2010; 36:69. http://dx.doi.org/10.1186/1824-7288-36-69

5. Mannan R, et al. Cyto-Radiological Diagnosis of Macrodystrophia Lipomatosa: A Report of Rare Entity With Review of Literature. Int J Med Health Sci. 2013 2(4): 469-471.

6. Murphey MD, Carroll JF, Flemming DJ et al. From the archives of the AFIP: benign musculoskeletal lipomatous lesions. Radiographics 2004; 24(5): 1433-1466.

7. Blacksin M, Barnes FJ, Lyons MM. MR diagnosis of macrodystrophia lipomatosa. AJR Am J Roentgenol 1992; 158(6): 1295-1297.

8. Rohilla S, Jain N, Sharma R, Dhaulakhandi DB. Macrodystrophia lipomatosa involving multiple nerves. J Orthop Traumatol. 2012; 13(1): 41-45. http://dx.doi. org/10.1007/s10195-011-0159-6 